\title{
Aboveground and belowground arthropods experience different relative influences of stochastic versus deterministic community assembly processes following disturbance
}

\author{
Scott Ferrenberg ${ }^{\text {Corresp., }}{ }^{1}$, Alexander S. Martinez ${ }^{1,2}$, Akasha M. Faist ${ }^{1}$ \\ 1 Department of Ecology and Evolutionary Biology, University of Colorado at Boulder, Boulder, Colorado, United States \\ 2 Department of Biological Sciences, Purdue University, West Lafayette, Indiana, United States \\ Corresponding Author: Scott Ferrenberg \\ Email address: sferrenberg@usgs.gov
}

Background. Understanding patterns of biodiversity is a longstanding challenge in ecology. Similar to other biotic groups, arthropod community structure can be shaped by deterministic and stochastic processes, with limited understanding of what moderates the relative influence of these processes. Disturbances have been noted to alter the relative influence of deterministic and stochastic processes on community assembly in various study systems, implicating ecological disturbances as a potential moderator of these forces. Methods. Using a disturbance gradient along a 5-year chronosequence of insectinduced tree mortality in a subalpine forest of the southern Rocky Mountains, Colorado, USA, we examined changes in community structure and relative influences of deterministic and stochastic processes in the assembly of aboveground (surface and litter-active species) and belowground (species active in organic and mineral soil layers) arthropod communities. Arthropods were sampled for all years of the chronosequence via pitfall traps (aboveground community) and modified Winkler funnels (belowground community) and sorted to morphospecies. Community structure of both communities were assessed via comparisons of morphospecies abundance, diversity, and composition. Assembly processes were inferred from a mixture of linear models and matrix correlations testing for community associations with environmental properties, and from null-deviation models comparing observed vs. expected levels of species turnover (Beta diversity) among samples. Results. Tree mortality altered community structure in both aboveground and belowground arthropod communities, but null models suggested that aboveground communities experienced greater relative influences of deterministic processes, while the relative influence of stochastic processes increased for belowground communities. Additionally, Mantel tests and linear regression models revealed significant associations between the aboveground arthropod communities and vegetation and soil properties, but no significant association among belowground arthropod communities and environmental 
factors. Discussion. Our results suggest context-dependent influences of stochastic and deterministic community assembly processes across different fractions of a spatially cooccurring ground-dwelling arthropod community following disturbance. This variation in assembly may be linked to contrasting ecological strategies and dispersal rates within above- and below-ground communities. Our findings add to a growing body of evidence indicating concurrent influences of stochastic and deterministic processes in community assembly, and highlight the need to consider potential variation across different fractions of biotic communities when testing community ecology theory and considering conservation strategies. 
1

2

3

4

5

6

7

8

9

10

11

12

13

14

15

16

17

18

19

20

21

22

23

24

25

26

27

Aboveground and belowground arthropods experience different relative influences of stochastic versus deterministic community assembly processes following disturbance

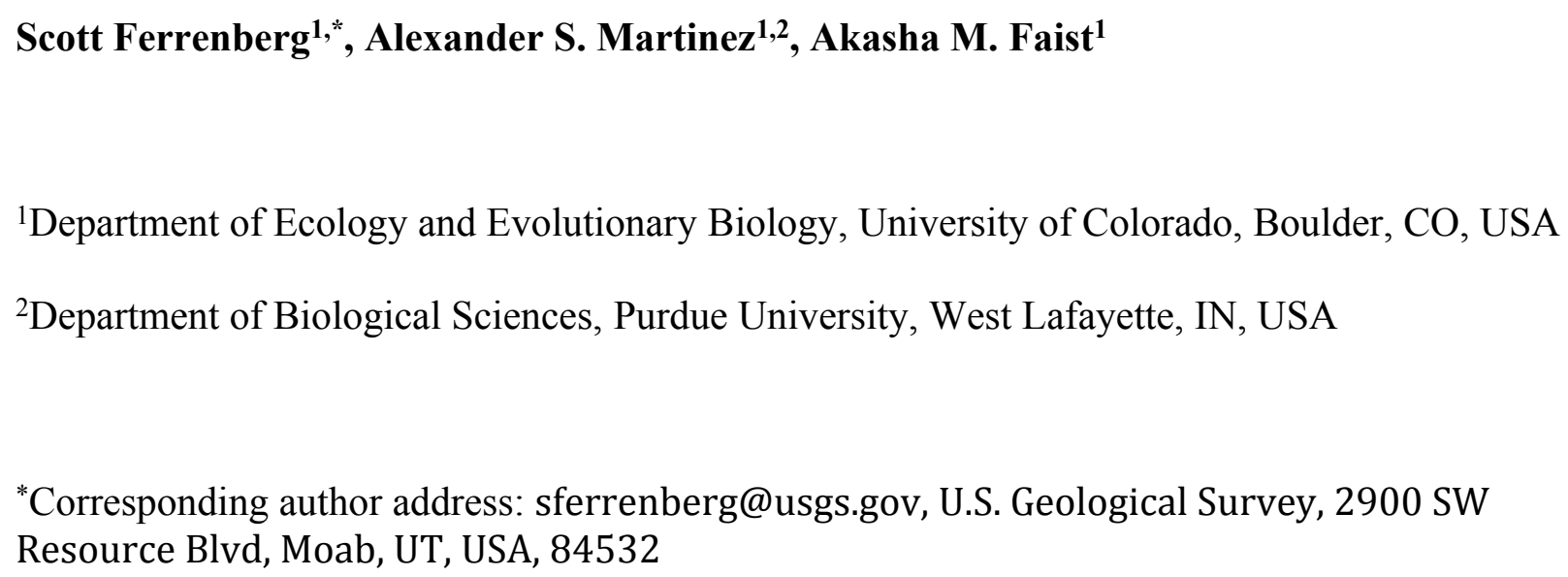




\section{Abstract}

29 Background. Understanding patterns of biodiversity is a longstanding challenge in ecology.

30 Similar to other biotic groups, arthropod community structure can be shaped by deterministic and

31 stochastic processes, with limited understanding of what moderates the relative influence of

32 these processes. Disturbances have been noted to alter the relative influence of deterministic and

33 stochastic processes on community assembly in various study systems, implicating ecological

34 disturbances as a potential moderator of these forces.

35 Methods. Using a disturbance gradient along a 5-year chronosequence of insect-induced tree 36 mortality in a subalpine forest of the southern Rocky Mountains, Colorado, USA, we examined

37 changes in community structure and relative influences of deterministic and stochastic processes

38 in the assembly of aboveground (surface and litter-active species) and belowground (species 39 active in organic and mineral soil layers) arthropod communities. Arthropods were sampled for

40 all years of the chronosequence via pitfall traps (aboveground community) and modified Winkler 41 funnels (belowground community) and sorted to morphospecies. Community structure of both

42 communities were assessed via comparisons of morphospecies abundance, diversity, and

43 composition. Assembly processes were inferred from a mixture of linear models and matrix

44 correlations testing for community associations with environmental properties, and from null-

45 deviation models comparing observed vs. expected levels of species turnover (Beta diversity)

46 among samples.

47 Results. Tree mortality altered community structure in both aboveground and belowground 48 arthropod communities, but null models suggested that aboveground communities experienced 49 greater relative influences of deterministic processes, while the relative influence of stochastic 50 processes increased for belowground communities. Additionally, Mantel tests and linear 
51 regression models revealed significant associations between the structure of aboveground

52 arthropod communities and vegetation and soil properties, but no significant association among

53 belowground arthropod communities and environmental factors.

54 Discussion. Our results suggest context-dependent influences of stochastic and deterministic 55 community assembly processes across different fractions of a spatially co-occurring ground-

56 dwelling arthropod community following disturbance. This variation in assembly may be linked

57 to contrasting ecological strategies and dispersal rates within above- and below-ground

58 communities. Our findings add to a growing body of evidence indicating concurrent influences

59 of stochastic and deterministic processes in community assembly, and highlight the need to

60 consider potential variation across different fractions of biotic communities when testing

61 community ecology theory and considering conservation strategies. 
62

63

64

65

66

67

\section{Introduction}

Understanding the processes governing the assembly of biotic communities is a longstanding goal in ecology. Deterministic processes have long been considered primary drivers of biodiversity patterns and niche-based theories of community assembly have amassed substantial support (e.g., MacArthur, 1957; Tilman, 1982). In contrast, theories proposing that stochastic processes can shape community structure-largely independent of species' traitshave also received support (MacArthur \& Wilson, 1967; Connell, 1978; Hubbell, 2001; Chave, 2004; Adler PB, HilleRisLambers \& Levine, 2007). Despite the apparent contradiction in theories, recent work has revealed simultaneous influences of deterministic and stochastic processes in the assembly and structure of a diverse range of biotic communities (Hart, 1992;

Thompson \& Townsend, 2006; Cadotte, 2007; Chase, 2007; Ellwood F, Manica \& Foster, 2009; Rominger, Miller \& Collins, 2009; Lepori \& Malmqvist, 2009; Fišer, Blejec \& Trontelj, 2012). As evidence of a concurrent influence of deterministic and stochastic assembly processes mounts, it also raises a key question: what determines the relative influence of stochastic and deterministic processes in community assembly?

Experimental evidence and theory have implicated a suite of factors controlling the relative influence of deterministic and stochastic processes in biotic communities-e.g., ecosystem productivity, regional biodiversity and dispersal rates, habitat connectivity, species' interactions and priority effects, and ecosystem disturbances (Chase, 2003; Chase, 2007; Jiang \& Patel, 2008; Collinge \& Ray, 2009; Lepori \& Malmqvist, 2009; Vergnon, Dulvy \& Freckleton, 2009; Stokes \& Archer, 2010). Of these factors, disturbances have been reported to increase (Chase, 2007; Jiang \& Patel, 2008) and decrease (Didham, Watts \& Norton, 2005; Leibold \& McPeek, 2006) the relative influence of both deterministic and stochastic processes, with recent 
85

86

87

90

91

92

94 95

work indicating that the importance of deterministic and stochastic processes can shift over time following disturbance (Lepori \& Malmqvist 2009; Ferrenberg et al., 2013; Nemergut et al., 2013). Evidence also indicates that assembly processes can vary among different fractions of a community in relation to environmental gradients, as well as species' ecological strategies, relative abundances, and dispersal rates (Thompson \& Townsend, 2006; Kraft et al., 2008; Ellwood F, Manica \& Foster, 2009; Rominger, Miller \& Collins, 2009; Barber \& Marquis, 2011; Langenheder \& Székely, 2011; Ingwell et al., 2012; Armitage, Ho \& Quigg, 2013; Márzuez \&Kolasa, 2013; Arnan et al. 2014; Guo et al., 2014). Understanding how ecological disturbances interact with these mechanisms to influence the strength of stochastic versus deterministic processes across different fractions of communities is an important next step for community assembly theory.

Ground-dwelling arthropod communities are ideal for the study of community assembly processes as they are composed of taxa representing a diverse range of ecological strategies and dispersal capabilities (Speight, Hunter \& Watt, 2008). Ground-dwelling arthropods in forested systems are also generally sensitive to a range of disturbance types and intensities, offering the chance to explore the effects of disturbance on assembly processes across different fractions of these communities (Ferrenberg et al., 2006; Moretti, Duelli \& Obrist, 2006; Lessard et al., 2011; Ober and DeGroote, 2011; Arnan et al., 2013; Delph et al., 2014; Williams et al., 2014; Brunbjerg et al., 2015). We used the opportunity presented by a multi-year bark beetle infestation to investigate the effects of tree mortality on assembly processes and community structure in ground-dwelling arthropod communities. We captured temporal variation by substituting space for time along a five-year chronosequence of tree mortality from bark beetles in a subalpine forest of the southern Rocky Mountains. Previous work indicates that bark beetle- 
108 induced tree mortality can rapidly alter understory and soil environments through changes in

109 microclimate (Wiedinmyer et al., 2012; Maness, Kushner \& Fung, 2013), soil hydrology

110 (Mikkelson et al., 2011), soil nutrient pools (Morehouse et al., 2008; Griffin, Turner \& Simard,

111 2011; Xiong et al. 2011; Griffin \& Turner 2012), and understory plant productivity (Brown et al.,

112 2010). Thus, we hypothesized (1) that tree mortality would alter arthropod community structure

113 over time, and (2) that changes in arthropod community structure would be linked to

114 deterministic influences, likely from influences of changing understory vegetation cover and soil

115 environments. Finally, substantial variation in the ecological strategies and dispersal potential

116 exists between aboveground arthropods (active on the ground surface and in upper litter layers)

117 and belowground arthropods (active in organic and mineral soil layers) (Blossey \& Hunt-Joshi,

118 2003; De Deyn \& Van der Putten, 2005; Joern \& Laws, 2013). Thus, we hypothesized (3) that

119 aboveground arthropods, which we assumed to have greater mobility and thus greater ability to

120 track changing environments, would exhibit stronger associations to local environmental

121 properties, while belowground arthropods would exhibit weaker associations to the environment

122 due to dispersal limitations.

123

124 Methods

125 Study site and chronosequence

126 We characterized arthropod communities, vegetation cover, and soil properties across a

127 five year chronosequence of tree mortality previously described in a study of soil bacteria by

128 Ferrenberg et al. (2014). Year zero (chronosequence year 0) represented samples from under

129 living trees that were never attacked by bark beetles, with remaining samples coming from four

130 categories representing trees killed by bark beetles one to four years prior to our study 
131 (chronosequence years 1-4). All sampled plots of the chronosequence were located under mature

132 limber pines (Pinus flexilis) at the University of Colorado's Mountain Research Station, $2900 \mathrm{~m}$

133 above sea level and approximately $11 \mathrm{~km}$ east of the Continental Divide in Boulder County,

134 Colorado, USA $\left(40^{\circ} \mathrm{N} ; 105^{\circ} \mathrm{W}\right)$. This site is characterized by low average annual temperatures

135 and a majority of annual precipitation falls as snow during winter months (Mitton \& Ferrenberg,

136 2012; Duhl et al., 2013; Ferrenberg et al., 2014). Tree mortality caused by the mountain pine

137 beetle (Dendroctonus pondersae) began in this site in 2006 and continued through 2012 in

138 susceptible pines that were monitored monthly allowing the establishment of the chronosequence

139 used here (Ferrenberg et al., 2014, Ferrenberg, Kane \& Mitton, 2014; Ferrenberg \& Mitton,

140 2014). This site is now characterized by a mosaic of living trees and trees in variable states of

141 decay.

142

\section{Arthropod, vegetation, and soil sampling}

144 Arthropods were sampled twice (June and August) to characterize communities during

145 the two month period when understory vegetation of this sub-alpine ecosystem is productive. We

146 sampled surface-dwelling arthropods (aboveground arthropods) from under 40 focal trees using a

147 combination of two pitfall traps per tree (i.e., 80 pitfall traps in total), with each trap placed

148 approximately one meter from the focal tree's trunk. Focal trees were surrounded by trees with

149 similar health status, were bounded from other sampling locations by live trees, and were evenly

150 divided among the five years of the insect-induced tree mortality chronosequence (i.e., eight

151 sample plots per each of the five chronosequence years, with the exception of the

152 chronosequence year four where both pitfall traps were removed from one plot by an animal

153 during the experiment leaving seven replicates). Focal trees were selected from a larger number 
154 of trees within each chronosequence year to avoid geographical clumping and maximize the

155 distance between sampling areas. Pitfall traps from under each focal tree were separated from

156 other traps by a minimum of $15 \mathrm{~m}$, while traps from within the same chronosequence year were

157 separated by $\geq 20 \mathrm{~m}$; distances as little as $5 \mathrm{~m}$ between pitfall traps have been verified as being

158 methodologically valid approaches for sampling arthropods in mixed woodland ecosystems via

159 Ward et al. (2001). Pitfall traps were $225 \mathrm{ml}$ plastic sample cups $(8 \mathrm{~cm}$ deep $\times 6 \mathrm{~cm}$ diameter $)$

160 that were inserted into organic and mineral soils with their lip flush to the ground surface. Each

161 trap contained $80 \mathrm{ml}$ of soapy water to act as a killing agent and preservative. Pitfalls were left

162 open for 72 hours in mid-June and another 72 hours in early-August 2011. At the end of each

163 sampling period, the traps were drained of excess soapy water, filled with $80 \% \mathrm{EtOH}$ and stored

164 at $-4^{\circ} \mathrm{C}$ until arthropods were sorted to morphospecies and counted. Arthropods primarily found

165 belowground in soil and organic layers were sampled from under 30 focal trees, six trees per

166 each of the five chronosequence years, via modified Winkler extractors. Samples for Winkler

167 extractors were collected in June and August by cutting a $10 \mathrm{~cm}$ diameter soil/litter plug to a

168 depth of $8 \mathrm{~cm}$ in the mineral soil and extracting an undisturbed column. Three column samples,

169 evenly spaced under each focal tree (one meter from the trunk) were composited together in

170 plastic bags in the field, returned to the lab within two hours, and placed into Winkler extractors

171 held under 80 watt lamps for 5 days. Collection cups for each extractor contained a 1:1 solution

172 of EtOH (100\%) and distilled $\mathrm{H}_{2} \mathrm{O}$ as a killing agent and preservative. The cups were capped and

173 stored at $-4^{\circ} \mathrm{C}$ until samples were sorted to morphospecies and counted. The majority of

174 arthropods captured were either adult holometabolous hexapods (i.e., beetles and ants), or adult

175 to late-stage instars of hemimetabolous hexapods and arachnids (i.e., collembola, mites, and

176 spiders). All captured individuals were sorted to morphospecies and identified to order, with 
177 hexapods further identified to families. The effectiveness of trapping effort at characterizing the

178 aboveground and belowground community was assessed via species accumulation curves created

179 in PC-ORD. In addition to arthropod sampling, cover by plant functional groups (herbaceous

180 plants, grasses, woody plants),vegetation species richness, and surface rock cover were measured

181 at peak biomass in a circular plot ( $1 \mathrm{~m}$ radius from each tree's trunk, or an area of roughly 4.1

$182 \mathrm{~m}^{2}$ ) placed around the trunk of each focal tree. All trees used in the study were of similar size,

183 but data for each tree was nevertheless corrected for small variations in tree size by converting

184 all aerial cover estimates to value per $\mathrm{m}^{2}$ of ground surface surveyed.

185 Measures of soil chemical properties from under each focal tree were completed in the

186 spring of 2011, prior to any plot disturbances due to arthropod sampling. Soil samples were a

187 composite of three, $130.5 \mathrm{~cm}^{3}$ cores from the top $5 \mathrm{~cm}$ of mineral soil (with all litter and visible

188 organic materials removed) collected evenly from around the tree and roughly $1.25 \mathrm{~m}$ from the

189 trunk. Following field extraction, all samples were transported on ice, and sieved through $2 \mathrm{~mm}$

190 mesh before biogeochemical analyses. Soil moisture, $\mathrm{pH}$, total $\% \mathrm{C}$ and $\% \mathrm{~N}, \mathrm{C}: \mathrm{N}$ ratio, $\mathrm{NH}_{4}^{+}$,

191 dissolved organic carbon (DOC), and microbial biomass were quantified using the detailed

192 methods described in Ferrenberg et al. (2013 \& 2014). In brief, soil moisture was determined via

193 gravimetric dry-down, $\mathrm{pH}$ was measured from a 1:5 ratio of soil to distilled and de-ionized $\mathrm{H}_{2} \mathrm{O}$,

194 and total $\mathrm{C}$ and $\mathrm{N}$ were determined using combustion. Measures of $\mathrm{NH}_{4}{ }^{+}, \mathrm{DOC}$, and microbial

195 biomass were determined via extractions from soil with $0.5 \mathrm{M} \mathrm{K}_{2} \mathrm{SO}_{4}$. Concentration of $\mathrm{NH}_{4}^{+}$

196 was determined from absorbance on a microplate reader, while DOC was determined using a

$197 \mathrm{TIC} / \mathrm{TOC}$ analyzer, with $\mathrm{DOC}=\mathrm{EC} / \mathrm{kEC}$ where $\mathrm{EC}=$ extractable $\mathrm{C}$ from soil and $\mathrm{kEC}=$

198 extractable C from microbial biomass (Beck et al., 1997). Soil chemistry data from the field site

199 are available from figshare (Knelman, 2014b). 


\section{Data analysis}

June and August arthropod samples were binned into one grand sample per focal tree

203 prior to analyses to match the primary goal of investigating assembly processes among years

204 following disturbance, as opposed to across a growing season. We then used non-metric

205 multidimensional scaling (NMDS) to visualize the community structure (at the level of

206 morphospecies) of above and belowground arthropods, and one-way PERMANOVA (followed

207 by pairwise PERMANOVA tests when the one-way tests resulted in $P<0.05$ ) to compare

208 communities among years of the tree mortality chronosequence. Both procedures were

209 completed in PC-ORD using Bray-Curtis distance matrices (McCune and Mefford 2011). Final

210 stress for NMDS runs indicated reasonably well fit, 2 dimensional solutions for both

211 aboveground and belowground arthropod communities, with stress interpretation following the

212 suggestions of Keough \& Quinn (2002) and Clarke (1993). Prior to PERMANOVA, the data for

213 both above and belowground communities were log transformed and relativized to the maximum

214 species abundance to account for differences in total abundances as described by McCune and

215 Medford (2002). Prior to all linear models, we verified that data were normally distributed via

216 Shapiro-Wilk tests, verified homogeneity of variances via O'Brien tests and analysis of mean

217 variances (ANOMV), and checked the distributions of residuals via Sharpio-Wilk tests and

218 normal quantile plots. We then compared arthropod total abundance (log transformed to meet

219 assumptions of normality), $\alpha$-diversity (sample-level species diversity calculated as the Shannon

220 diversity index, $\mathrm{H}^{\prime}$ ), as well as soil chemical measures, and vegetation species richness and cover

221 using one-way ANOVA followed by post hoc LSD means comparisons (Kruskal-Wallis test

222 followed by Wilcoxon pairwise comparisons when assumptions of normality were not met). 
We used null deviation analysis to further assess assembly processes structuring both

224 above and belowground arthropod communities across the tree mortality chronosequence. Null

225 deviation analyses used alone can be difficult to interpret and were employed here as a

226 complimentary approach to linear modeling and Mantel tests for assessing the factors structuring

227 arthropod communities; detailed description of null deviation methods and R code are available

228 from Chase \& Myers, (2011) and Tucker et al., (2015). In brief, the null deviation method

229 assesses how observed $\beta$-diversity patterns deviate from communities randomly assembled in

230 silico from the regional species pool. This approach disentangles the dissimilarity in structure

231 across samples from dissimilarity driven by changes in $\alpha$ - (local) and $\gamma$ - (regional) diversity. We

232 calculated null deviation as the relative difference of observed $\beta$-diversity from null modeled $\beta$ -

233 diversity-i.e., $\left(\beta_{\mathrm{obs}}-\beta_{\text {null }}\right) / \beta_{\text {null }}$, where $\beta$-diversity was measured as Sørenson-Czekanowski binary

234 dissimilarity. For each sample, null modeled $\beta$-diversity was calculated from 10000 randomly

235 assembled communities. We compared null deviation values of aboveground and belowground

236 communities via a permutation test that resamples from null deviation values generated by five

237 unique null deviation simulations. Permutation tests shuffle the labels of factors (i.e.,

238 aboveground vs belowground group labels are shuffled among null deviation output values) to

239 compare the number of differences between factors that are more extreme than the difference

240 with unshuffled factors (i.e., differences from aboveground null deviation value - belowground

241 null deviation value vs. differences from the same calculation when the labels are shuffled) (Yu,

242 2003). The null hypothesis of the permutation test is that the mean null deviations for

243 aboveground and belowground arthropod communities within years of the chronosequence are

244 equal; the reported P-values indicate the likelihood that observed differences in null deviation

245 among the communities is due to chance (i.e., smaller P-values indicate lower likelihood that the 
246 two groups differ by chance alone).

$247 \quad$ Following null modeling, we examined possible relationships of vegetation and soil

248 properties (independent variables) with aboveground/belowground arthropod community

249 structure (dependent variables) via Mantel tests. Mantel tests were completed using Sørenson

250 distance matrices for arthropod communities and Euclidean distance matrices for environmental

251 factors. We also examined possible relationships between vegetation and soil properties

252 (independent variables) and arthropod abundance and diversity (dependent variables) via

253 stepwise multiple regressions. Independent variables used in both Mantel tests and regression

254 models included: soil moisture, $\mathrm{pH}, \% \mathrm{C}, \% \mathrm{~N}, \mathrm{C}: \mathrm{N}, \mathrm{DOC}, \mathrm{NH}_{4}{ }^{+}$, vegetation species richness,

255 total vegetation cover, forb cover, graminoid cover, tree cover, shrub cover, and rock cover.

256 Best-fit multiple-regression models were selected via Bayesian information criterion (BIC)

257 values, with the lowest $B I C$ score indicating the model that explained the most variation in

258 arthropod measures with the smallest number of factors to avoid over-fitting. Independent

259 variables retained in regression models were examined for collinearity via correlation

260 coefficients (i.e., collinear measures with $P>0.05$ were avoided).

261

262 Results

263

264

265

266

267

268

269

\section{Arthropod community structure and tree mortality}

We captured a total of 10757 individual arthropods, representing 39 morphospecies (hereafter referred to as "species") collectively across all aboveground (23 spp., sampled via pitfall traps) and belowground samples (20 spp., sampled via modified Winkler extractors) with four species shared among both groups (Supplemental Table 1, Supplemental Figure 1). There was an average of 11 species in each aboveground sample across the chronosequence; with 14 of 
270 the 23 species found in all five years of the chronosequence. For belowground arthropods, there

271 was an average of 5 species per sample, with 6 of the 20 belowground species found in all

272 chronosequence years.

273 Aboveground arthropod species richness (displayed throughout as the mean $\pm 1 \mathrm{SE}$ ) did

274 not significantly differ across years, with the lowest richness of $9.6( \pm 1.1)$ found three years

275 after tree mortality and the highest richness of $11.4( \pm 2.5)$ found four years after tree mortality

276 in the final year of the chronosequence. Tree mortality did significantly alter aboveground

277 arthropod abundance $(F=6.7$, d.f. $=4,35, P=0.0004$; Figure 1$)$ and species diversity $\left(\mathrm{H}^{\prime}\right),(F=$

2788.3, d.f. $=4,35, P<0.0001$; Figure 1). In the belowground arthropod community, tree mortality

279 did not have a significant effect on either arthropod abundance or diversity $\left(\mathrm{H}^{\prime}\right)(P>0.05$; Figure

280 1). Despite the variable effects of tree mortality on abundance and diversity between above and

281 belowground communities, tree mortality did cause significant shifts $(P<0.05)$ in community

282 structure in both the aboveground and belowground arthropod communities. Changes in

283 community structure were primarily driven by differences between communities of years 3 and 4

284 and those in years 1 and 2 for aboveground arthropods, and a difference between year 3 and year

2850 (undisturbed) for both above and belowground communities (Figure 2, Table 1).

286

287 Community assembly processes

288

289

We assessed community assembly processes via the null deviation approach (Chase \&

290 Myers, 2011). This approach compares observed levels of $\beta$-diversity in field samples to the $\beta$ -

291 diversity of samples randomly assembled in computer simulations to produce an index that

292 ranges from \pm 1 to 0 , where values closer to \pm 1 indicate greater deviation from random

293 (suggesting a stronger relative influence of deterministic assembly processes). Null deviation 
294 values suggested that tree mortality altered the relative influences of deterministic and stochastic

295 assembly processes in both aboveground and belowground arthropod communities. Following

296 tree mortality, null deviation values for belowground communities declined in absolute value

297 across years 1 through 4 of the chronosequence reaching a low of $|0.07|$, indicating more

298 stochastic assemblages (Figure 3, Supplemental Table 2). In contrast, deviation from randomly

299 assembled communities increased slightly for aboveground communities in years 1 and 3 after

300 tree mortality, suggesting a stronger and/or stable relative influence of deterministic processes on

301 community assembly (Figure 3 ). Permutation tests revealed a significant difference $(\mathrm{P}<0.05)$ in

302 the null deviation of aboveground and belowground communities for years 2 and 3 of the

303 chronosequence (Figure 3). However, an increase in stochastic influences in aboveground

304 communities was apparent in the final year of the chronosequence (year 4; Figure 3,

305 Supplemental Table 2) suggesting that above- and belowground communities may have returned

306 to experiencing similar relative influences of different assembly processes.

307

308

309

310

311

312

313

314

317

\section{Associations of arthropod community structure and vegetation/soil properties}

Tree mortality led to variation in soil chemical properties across the chronosequence (Supplemental Table 2, see also Ferrenberg et al., 2014), and caused significant changes in understory vegetation cover $(F=4.6, d . f .=4,35, P=0.004$; Figure 4) and vegetation species richness $(F=4.8$, d.f. $=4,35, P=0.004$; Figure 4). Differences in relative cover of plant functional groups was also found across the chronosequence: forb cover increased seven-fold between year 0 and 3 (Table 2), and both graminoid and shrub cover increased by an order of magnitude or more between year 0 and 2 (Table 2).

$$
\text { Mantel tests revealed a significant association between aboveground arthropod }
$$
communities and combined vegetation/soil properties $(r=0.26, P=0.005)$, while belowground 
318 communities were not significantly associated with vegetation/soil properties $(r=0.05, P>$

319 0.05). Partial Mantel tests further indicated that Aboveground arthropod communities were

320 significantly associated with total vegetation cover $(r=0.28, P=0.016)$, graminoid cover $(r=$

$3210.34, P=0.018)$, shrub cover $(r=0.20, P=0.030)$, and soil $\mathrm{NH}_{4}{ }^{+}$concentration $(r=0.16, P=$

322 0.026); while all other environmental variables were not significantly associated $(P>0.05)$ with

323 the arthropod community. Stepwise multiple regression models identified significant

324 relationships between vegetation/soil properties and aboveground arthropod abundance and

325 diversity, but no significant relationships for belowground arthropods $(P<0.05)$. Specifically,

326 aboveground arthropod abundance was significantly associated with total vegetation cover,

327 vegetation species richness, and total soil carbon $(\% \mathrm{C})$; while arthropod species diversity

328 (Shannon $\left.\mathrm{H}^{\prime}\right)$ was related to shrub and rock cover, and total soil carbon concentration $(\% \mathrm{C})$.

330 Discussion

331 We investigated the effects of tree mortality on the structure and assembly of arthropod

332 communities (characterized at the level of morphospecies) along a five-year chronosequence of

333 bark beetle-induced tree death in a subalpine conifer forest. Given the existence of substantial

334 variation in the ecology and dispersal potential of aboveground versus belowground arthropods

335 (Blossey \& Hunt-Joshi, 2003; De Deyn \& Van der Putten, 2005; Joern \& Laws, 2013), we

336 examined both communities separately with the goal of understanding whether the disturbance

337 from tree mortality had contrasting effects on these different fractions of the ground-dwelling

338 arthropod community. We found support for our first hypothesis that tree mortality caused a shift

339 in arthropod community structure; a result that was true for both above and belowground

340 arthropod assemblages (Figure 2, Table 1). However, tree mortality appeared to have a greater 
341 effect on the structure of the aboveground arthropod community than on the belowground, as

342 evidenced by the changes in abundance and diversity in aboveground arthropods but not in

343 belowground arthropods (Figure 1). We also observed changes in understory vegetation cover

344 and vegetation species richness following tree mortality (Figure 4, Table 2), as well as variation

345 in edaphic properties (Supplemental Table 1). Yet despite changes in vegetation and soil

346 properties, we found only mixed support for our second hypothesis that changes in the

347 understory environment following tree mortality would lead to an increased influence of

348 deterministic processes in the assembly of arthropod communities. Specifically, null deviation

349 models (Chase \& Myers, 2011) comparing the relative deviation of observed communities from

350 communities randomly assembled in silico suggested that both aboveground and belowground

351 communities experience a similar balance of assembly processes in undisturbed sites (Figure 3).

352 Yet following tree mortality, we observed a stable, stronger relative influences of deterministic

353 processes in the assembly of aboveground communities than apparent for belowground

354 communities which experienced a significant increase in the relative influence of stochastic

355 assembly processes (Figure 3).

356 A stronger influence of deterministic processes in structuring aboveground versus

357 belowground communities is further supported by multiple regression models and Mantel tests of 358 association. Specifically, multiple regression models found a significant relationship of both 359 arthropod abundance and diversity to a mixture of vegetation and soil properties (Table 3). Also, 360 in Mantel tests of association, the overall community structure (the combination of composition, 361 diversity and abundance) of aboveground arthropods was significantly associated with various 362 environmental factors including: total vegetation cover, graminoid (grass) cover, shrub cover and 363 soil ammonium $(\mathrm{NH} 4+$ ) concentrations - a measure that often increases in the short term after 
364 tree mortality due to a decline in overall uptake (Morehouse et al. 2008; Mikkelson et al. 2013).

365 At the same time, neither analysis found a link between belowground community structure and

366 environmental factors we measured here, suggesting a weaker relationship to local

367 environmental properties following tree mortality. However, it is possible that other

368 environmental factors that were not sampled in our study have an influence on belowground

369 arthropod community structure. At the same time, we utilized soil chemical measures collected

370 several months before sampling arthropod communities. This time lag between sampling

371 campaigns likely allowed for some change in soil chemical pools which could have reduced the

372 apparent influence of soil properties on arthropod communities. Nevertheless, the model

373 associations between arthropod abundance and diversity suggest that the return to a similar

374 aboveground arthropod community in the final year of chronosequence (year 4) as found in the

375 undisturbed (year 0) portion of our chronosequence (Figure 2, Table 3) is driven by arthropod

376 responses to vegetation properties and soil carbon dynamics - factors that have similar dynamics

377 to aboveground arthropods following tree mortality (Figure 4, Supplemental Table 1).

378 Bark beetle infestations have impacted enormous swaths of western North America,

379 leaving billions of dead trees in their wake, often at higher elevations and latitudes than

380 previously recorded due to rapidly warming temperatures (Mitton \& Ferrenberg, 2012; Mitton \&

381 Ferrenberg, 2014). Tree mortality during recent epidemics has been linked to increased

382 understory vegetation productivity (Brown et al., 2010); as well as changes in forest

383 microclimate (Wiedinmyer et al., 2012; Maness, Kushner \& Fung, 2013), soil hydrology

384 (Mikkelson et al., 2011), and soil nutrient pools (Morehouse et al., 2008; Griffin, Turner \&

385 Simard, 2011; Xiong et al., 2011; Griffin \& Turner, 2012). Thus, a shift in ground-dwelling

386 arthropod community structure in response to tree mortality is not surprising given arthropod 
387 community sensitivity to changes in vegetation and litter cover from various forest disturbances,

388 ranging from severe wildfires to relatively minor perturbations such as manipulations of coarse

389 woody debris (Ferrenberg et al., 2006; Moretti, Duelli \& Obrist, 2006; Lessard et al., 2011; Ober

390 \& DeGroote, 2011; Armitage, Ho \& Quigg, 2013; Arnan et al., 2014; Delph et al., 2014;

391 Williams et al., 2014; Brunbjerg et al., 2015). Additionally, the shift in arthropod community

392 structure we found here joins recent reports indicating that bark beetle-induced tree mortality

393 alters the structure of soil fungal communities (Treu et al., 2014; Štursová et al., 2014) and

394 nematode community trophic composition (Xiong et al., 2011) of European and North American

395 conifer forests, respectively. Considered collectively, the changes in arthropod communities and

396 understory vegetation structure we found here, and the changes in nematode and fungal

397 communities found in other forests would seem to indicate that tree mortality during insect

398 epidemics can widely affect forest-understory biotic communities. However, our finding that

399 surface dwelling arthropods are more strongly influenced by environmental properties than

400 belowground arthropods suggests the presence of complicated aboveground-belowground

401 linkages affecting responses in these systems (De Deyn \& Van der Putten, 2005; Bardgett \&

402 Wardle, 2010).

403 Given changes in the forest understory environment, we initially expected that changes in

404 arthropod community structure following tree mortality would be linked to niche dynamics.

405 However, the structure of biotic communities can be shaped by either deterministic processes

406 (often interchanged with 'niche-based processes') or stochastic processes (sometime conflated

407 with 'neutral processes'), and an increasing amount of evidence indicates a simultaneous

408 influence of both processes in arthropod and macro-invertebrate communities (Hart, 1992;

409 Thompson \& Townsend, 2006; Chase, 2007; Chase et al., 2009; Ellwood F, Manica \& Foster, 
410 2009; Rominger, Miller \& Collins, 2009; Lepori \& Malmqvist, 2009; Barber \& Marquis, 2011;

411 Fišer, Blejec \& Trontelj, 2012; Joern \& Laws, 2013; Kitching, 2013). The variation we found in

412 strength of assembly processes across fractions of the arthropod community indicates that

413 disturbance can either increase or decrease the ratio of deterministic to stochastic processes

414 within a community (e.g., Didham, Watts \& Norton, 2005; Leibold \& McPeek, 2006; Chase,

415 2007; Lepori \& Malmqvist, 2009). While this outcome seems to complicate the goal of

416 understanding how disturbance impacts community assembly, the relationship between

417 disturbance and assembly processes is likely dependent upon regional species diversity, species

418 dispersal rates, and the spatial and temporal scale of disturbances — all of which are expected to

419 vary across systems and taxonomic groups (Cottenie, 2005; Reed et al., 2000; Mackay \& Currie,

420 2001; Mouquet \& Loreau, 2002; Chase, 2003; Tuomisto, Ruokolainen \& Yli-Halla, 2003;

421 Vanschoenwinkel et al., 2007; Rominger, Miller \& Collins, 2009; Lepori \& Malmqvist, 2009;

422 Márquez \& Kolasa, 2013). The interaction of these variables, alongside the effects of

423 disturbances, in moderating the balance of deterministic and stochastic assembly processes are

424 all but certain to generate a range of context-dependent outcomes across studies. Nevertheless, in

425 our study system, a combination of temporal gradients and influences of distributions and

426 dispersal rates likely explain the contrasting influences of deterministic and stochastic processes

427 for above and belowground arthropod communities. Specifically, dispersal limitations likely

428 inhibit the rate of niche-tracking and species sorting by belowground arthropods, at the same

429 time as stochastic dispersal and heterogeneous distributions (linked to ecological strategies and

430 landscape legacy) influence community assembly in the short term following tree mortality.

431 Given enough time for dispersal, biotic-interactions and environmental filtering would begin to

432 influence belowground arthropods, thereby explaining the greater relative influence of 
433 deterministic processes in undisturbed sites of the chronosequence (Figure 3). This scenario

434 agrees with recent work in passively dispersed soil microbial communities where disturbance

435 caused an initial increase in stochastic influences on community assembly-likely due to a

436 decline in species abundance at the same time as stochastic dispersal affected recolonization-

437 with a shift toward deterministic influences over time as species diversity and abundance

438 increased, leading to more biotic interactions and filtering (Ferrenberg et al., 2013; Nemergut et

439 al., 2013). Meanwhile, aboveground arthropods, often being larger and more capable of rapid

440 dispersal into suitable habitats than belowground arthropods, were more likely to experience

441 biotic interactions and species sorting over the spatial and temporal scale of tree mortality in this

442 forested system. Yet if these communities reach an equilibrium, stochastic processes could

443 eventually exert greater levels of influence at larger spatial and temporal scales - possibly

444 explaining the apparent increase in stochastic influences in aboveground communities in the final

445 year of the chronosequence. This hypothesized scenario for aboveground communities is further

446 supported both by linear (multiple regression) and permutation models (Mantel correlation) used

447 here, and also by studies in other arthropod and macro-invertebrate dominated systems where

448 disturbance increased deterministic processes via environmental filtering, with an eventual shift

449 toward greater influence of stochastic processes over time (Chase, 2003; Chase, 2007; Lepori \&

450 Malmqvist, 2009).

451

\section{Conclusions}

453 Forest disturbances due to insect epidemics are historically natural events that have

454 increased in frequency due to warming climate and other global and regional factors (Mitton \&

455 Ferrenberg, 2012; Ferrenberg, Kane \& Mitton, 2014). Understanding how biotic communities 
456 respond to increasing rates of forest disturbance can not only offer insightful tests of ecological

457 theory, but can also help to inform forest management strategies for dealing with large-scale tree

458 mortality. We found tree mortality during a bark beetle infestation altered the structure of

459 aboveground and belowground arthropod communities. Null deviation models suggested that

460 these different fractions of the arthropod community experience different relative influences of

461 assembly processes following disturbance: with aboveground arthropod communities more

462 influenced by deterministic processes and belowground communities by stochastic. Likewise,

463 aboveground arthropod community structure was linked to vegetation and soil properties, while

464 the belowground community had no clear links to environmental characteristics. An important

465 next step will be determining if arthropod communities assembled via divergent processes have

466 variable influences on ecosystem processes and functioning. One possibility is that stochastically

467 assembled communities have less direct links to ecosystem processes, or perhaps less predictable

468 influences than do deterministically assembled communities (Ferrenberg et al., 2013; Ferrenberg

469 et al., 2014; Nemergut et al., 2013; Knelman \& Nemergut, 2014). This scenario might help to

470 resolve the enigma of why ground-dwelling arthropod assemblages influence ecosystem

471 processes in some systems (Seastedt \& Crossley, 1984; González \& Seastedt, 2001; Bradford et

472 al., 2002; Vasconcelos \& Laurance, 2005; Finér et al., 2013), but not in others (Seastedt, 1984;

473 Hättenschwiler, Tiunov \& Scheu, 2005).

474

\section{Acknowledgements}

476 We thank the University of Colorado's Biological Sciences Initiative, the University of

477 Colorado's Mountain Research Station, and Jeffry Mitton for logistical support. We are indebted

478 to the late Diana Nemergut for her insights and support throughout this research. Our manuscript 
479 was improved by the thoughtful comments of Manu Saunders and two anonymous reviewers. 


\section{References}

482 Adler PB, HilleRisLambers J, Levine JM (2007) A niche for neutrality. Ecol. Lett. 10: 95-104.

483

484

485

486

487

488

489

490

491

492

493

494

495

496

497

498

499

500

501

502

503

504

505

506

507

508

509

510

511

Armitage AR, Ho CK, Quigg A (2013) The interactive effects of pulsed grazing disturbance and patch size vary among wetland arthropod guilds. PloS one 8(10): e76672

Arnan X, Cerdá X, Rodrigo A, Retana J (2013) Response of ant functional composition to fire. Ecography 36: 1182-1192

Barber NA, Marquis RJ (2011) Leaf quality, predators, and stochastic processes in the assembly of a diverse herbivore community. Ecology 92: 699-708

Bardgett RD, Wardle DA (2010) Aboveground-belowground linkages: biotic interactions, ecosystem processes, and global change (pp. 10-11pp). Oxford: Oxford University Press.

Beck T, Joergensen G, Kandeler E, Makeschin F, Nuss E, Oberholzer HR, Scheu S (1997) An interlaboratory comparison of ten different ways of measuring soil microbial biomass C. Soil Biol. Biochem. 29: $1023-1032$

Blossey B, Hunt-Joshi TR (2003) Belowground herbivory by insects: influence on plants and aboveground herbivores. Annu. Rev. Entomol. 48: 521-547

Bradford MA, Jones TH, Bardgett RD, Black HI, Boag B, Bonkowski M, Cook R, Eggers T, Gange AC, Grayston SJ, Kandeler E, McCaig AE, Newington JE, Prosser JI, Setälä H, Staddon PL, Tordoff GM, Tscherko D, Lawton JH (2002) Impacts of soil faunal community composition on model grassland ecosystems. Science 298: 615-618

Brown M, Black TA, Nesic Z, Foord VN, Spittlehouse DL, Fredeen AL, Grant NJ, Burton PJ, Trofymow JA (2010) Impact of mountain pine beetle on the net ecosystem production of lodgepole pine stands in British Columbia. Agric. For. Meteorol. 150: 254-264

Brunbjerg AK, Jørgensen GP, Nielsen KM, Pedersen ML, Svenning JC, Ejrnæs R (2015) Disturbance in dry coastal dunes in Denmark promotes diversity of plants and arthropods. Biol. Conserv. 182: 243-253

Cadotte MW (2007) Concurrent niche and neutral processes in the competition-colonization model of species coexistence. Proc. R. Soc. B. Biol. 274: 2739-2744

Chase JM (2003) Community assembly: when should history matter? Oecologia 136: 489-498

Chase JM (2007) Drought mediates the importance of stochastic community assembly. Proc Natl Acad Sci USA 104:17430-17434

Chase JM, Myers JA (2011) Disentangling the importance of ecological niches from stochastic processes across scales. Philos. Trans. R. Soc. Lond. Biol. 366: 2351-2363

Chase JM, Biro EG, Ryberg WA, Smith KG (2009) Predators temper the relative importance of stochastic processes in the assembly of prey metacommunities. Ecol. Lett. 12: 1210-1218

Chave J (2004) Neutral theory and community ecology. Ecol. Lett. 7: 241-253 
530 Clarke KR (1993) Non-parametric multivariate analyses of changes in community structure. Australian

531

532

533

534

535

536

537

538

539

540

541

542

543

544

545

546

547

548

549

550

551

552

553

554

555

556

557

558

559

560

561

562

563

564

565

566

567

568

569

570

571

572

573

574

575

576

577

578

579

580

Journal of Ecology 18: 117-143

Collinge SK, Ray C (2009) Transient patterns in the assembly of vernal pool plant communities. Ecology 90: 3313-3323

Connell JH (1978) Diversity in tropical rain forests and coral reefs. Science 199: 1302-1310

Cottenie K (2005) Integrating environmental and spatial processes in ecological community dynamics. Ecol. Lett. 8: 1175-1182

De Deyn GB, Van der Putten WH (2005) Linking aboveground and belowground diversity. Trends Ecol. Evol. 20: 625-633

Delph RJ, Clifford MJ, Cobb NS, Ford PL, Brantley SL (2014) Pinyon pine mortality alters communities of ground-dwelling arthropods. West. N. Am. Naturalist 74: 162-184

Didham RK, Watts CH, Norton DA (2005) Are systems with strong underlying abiotic regimes more likely to exhibit alternative stable states? Oikos 110:409-416

Duhl TR, Gochis D, Guenther A, Ferrenberg S, Pendall E (2013) Emissions of BVOC from lodgepole pine in response to mountain pine beetle attack in high and low mortality forest stands. Biogeosci. 10:483-499

Ellwood F, Manica A, Foster WA (2009) Stochastic and deterministic processes jointly structure tropical arthropod communities. Ecol. Lett. 12: 277-284

Ferrenberg S, Knelman JE, Jones JM, Beals SC, Bowman WD, Nemergut DR (2014a) Soil bacterial community structure remains stable over a 5 -year chronosequence of insect-induced tree mortality. Front. Microbiol. 5:681

Ferrenberg S, Kane JM, Mitton JB (2014b) Resin duct characteristics associated with tree resistance to bark beetles across lodgepole and limber pines. Oecologia 174:1283-1292

Ferrenberg S, Mitton JB (2014) Smooth bark surfaces can defend trees against insect attack: resurrecting a 'slippery'hypothesis. Funct. Ecol. 28: 837-845

Ferrenberg S, O’Neill SP, Knelman JE, Todd B, Bradley D, Robinson T, Schmidt SK, Townsend AR, Williams MW, Cleveland CC, Melbourne BA, Jiang L, Nemergut D (2013) Changes in assembly processes in soil bacterial communities following a wildfire disturbance. ISME J. 7:1102-1111

Ferrenberg SM, Schwilk DW, Knapp EE, Groth E, Keeley JE (2006) Fire decreases arthropod abundance but increases diversity: early and late season prescribed fire effects in a Sierra Nevada mixed-conifer forest. Fire Ecol. 2: 79-102

Finér L, Jurgensen MF, Domisch T, Kilpeläinen J, Neuvonen S, Punttila P, Risch AC, Ohashi M, Niemelä P (2013) The role of wood ants (Formica rufa group) in carbon and nutrient dynamics of a boreal Norway spruce forest ecosystem. Ecosystems 16: 196-208

Fišer C, Blejec A, Trontelj P (2012) Niche-based mechanisms operating within extreme habitats: a case study of subterranean amphipod communities. Biol. Lett. rsbl20120125.

Peer] reviewing PDF | (2016:02:9286:2:1:NEW 26 Aug 2016) 
581

582

583

584

585

586

587

588

589

590

591

592

593

594

595

596

597

598

599

600

601

602

603

604

605

606

607

608

609

610

611

612

613

614

615

616

617

618

619

620

621

622

623

624

625

626

627

628

629

630

631

González G, Seastedt TR (2001) Soil fauna and plant litter decomposition in tropical and subalpine forests. Ecology 82: 955-964

Griffin JM, Turner MG, Simard M (2011) Nitrogen cycling following mountain pine beetle disturbance in lodgepole pine forests of Greater Yellowstone. Forest Ecol. Manag. 261: 1077-1089

Guo H, Więski K, Lan Z, Pennings SC (2014) Relative influence of deterministic processes on structuring marsh plant communities varies across an abiotic gradient. Oikos 123: 173-178

Hart DD (1992) Community organization in streams: the importance of species interactions, physical factors, and chance. Oecologia 91: 220-228

Hättenschwiler S, Tiunov AV, Scheu S (2005) Biodiversity and litter decomposition in terrestrial ecosystems. Annu. Rev. Ecol. Evol. S. 191-218

Hubbell SP (2001) The Unified Neutral Theory of Biodiversity and Biogeography. Princeton University Press, Princeton, NJ

Ingwell LL, Miller-Pierce M, Trotter III RT, Preisser EL (2012) Vegetation and invertebrate community response to Eastern Hemlock decline in southern New England. Northeast. Nat. 19: 541-558.

Jiang L, Patel SN (2008) Community assembly in the presence of disturbance: a microcosm experiment. Ecology 89:1931-1940

Joern A, Laws AN (2013) Ecological mechanisms underlying arthropod species diversity in grasslands. Annu. Rev. Entomol. 58: 19-36

Keough MJ, Quinn GP (2002) Experimental design and data analysis for biologists. Cambridge University Press, New York NY

Kitching RL (2013) Niches and neutrality: community ecology for entomologists. Aust. J. Entomol. 52: $1-7$

Knelman JE, Nemergut DR (2014) Changes in community assembly may shift the relationship between biodiversity and ecosystem function. Front. Microbiol. 5

Knelman J (2014b) Mappingfile/metadata:soil bacterial community structure remains stable over a fiveyear chronosequence of insect-induced tree mortality. figshare. doi:10.6084/m9.figshare. 1252208

Kraft NJ, Valencia R, Ackerly DD (2008) Functional traits and niche-based tree community assembly in an Amazonian forest. Science 322: 580-582

Langenheder S, Székely AJ. (2011). Species sorting and neutral processes are both important during the initial assembly of bacterial communities. ISME J 5:1086-1094.

Leibold MA, McPeek MA (2006) Coexistence of the niche and neutral perspectives in community ecology. Ecology 8:1399-1410

Lepori F, Malmqvist B (2009) Deterministic control on community assembly peaks at intermediate levels of disturbance. Oikos 118: 471-479 
632

633

634

635

636

637

638

639

640

641

642

643

644

645

646

647

648

649

650

651

652

653

654

655

656

657

658

659

660

661

662

663

664

665

666

667

668

669

670

671

672

673

674

675

676

677

678

679

680

681

682

Lessard JP, Sackett TE, Reynolds WN, Fowler DA, Sanders NJ (2011) Determinants of the detrital arthropod community structure: the effects of temperature and resources along an environmental gradient. Oikos 120: 333-343

MacArthur R, Wilson E (1967) The Theory of Island Biogeography. Princeton University Press, Princeton NJ

MacArthur RH (1957) On the relative abundance of bird species. P. Natl. Acad. Sci. USA 43: 293

Mackey RL, Currie DJ (2001) The diversity-disturbance relationship: is it generally strong and peaked? Ecology 82: 3479-3492

Maness H, Kushner PJ, Fung I (2013) Summertime climate response to mountain pine beetle disturbance in British Columbia. Nat. Geosci. 6: 65-70

Márquez JC, Kolasa J (2013) Local and regional processes in community assembly. PloS one 8(1): e54580.

McCune B, Medford MJ (2002) Analysis of ecological communities. Gleneden Beach, OR: MJM

Software

McCune B, Mefford MJ (2011) PC-ORD. Multivariate Analysis of Ecological Data. Version 6.0. Gleneden Beach, OR: MjM Software

Mikkelson KM, Bearup LA, Maxwell RM, Stednick JD, McCray JE, Sharp JO (2013) Bark beetle infestation impacts on nutrient cycling, water quality and interdependent hydrological effects. Biogeochem. 115: 1-21

Mitton JB, Ferrenberg SM (2012) Mountain Pine Beetle Develops an Unprecedented Summer Generation in Response to Climate Warming. Am. Nat. 179:E163-E171

Mitton JB, Ferrenberg S (2014) Field Studies Demonstrate Bivoltinism in the Mountain Pine Beetle. Am. Nat. 184: 797-801

Morehouse K, Johns T, Kaye J, Kaye M (2008) Carbon and nitrogen cycling immediately following bark beetle outbreaks in southwestern ponderosa pine forests. Forest Ecol. Manag. 255: 2698-2708

Moretti M, Duelli P, Obrist MK (2006) Biodiversity and resilience of arthropod communities after fire disturbance in temperate forests. Oecologia 149: 312-327

Mouquet N, Loreau M (2002) Coexistence in metacommunities: the regional similarity hypothesis. Am. Nat. 159: 420-426

Nemergut DR, Schmidt SK, Fukami T, O'Neill SP, Bilinski TM, Stanish LF, Knelman JE, Darcy JL, Lynch RC, Wickey P, Ferrenberg S (2013) Patterns and processes of microbial community assembly. Microbiol. Mol. Biol. R. 77: 342-356

Ober HK, DeGroote LW (2011) Effects of litter removal on arthropod communities in pine plantations. Biodivers. Conserv. 20: 1273-1286 
683 Reed DC, Raimondi PT, Carr MH, Goldwasser L (2000) The role of dispersal and disturbance in

684

685

686

687

688

689

690

691

692

693

694

695

696

697

698

699

700

701

702

703

704

705

706

707

708

709

710

711

712

713

714

715

716

717

718

719

720

721

722

723

724

725

726

727

728

729

730

731

732

733

determining spatial heterogeneity in sedentary organisms. Ecology 81: 2011-2026

Rominger AJ, Miller TE, Collins SL (2009) Relative contributions of neutral and niche-based processes to the structure of a desert grassland grasshopper community. Oecologia 161: 791-800

Seastedt TR (1984) The role of microarthropods in decomposition and mineralization processes. Annu. Rev. Entomol. 29: 25-46

Seastedt TR, Crossley DA (1984) The influence of arthropods on ecosystems. BioScience 157-161

Speight, MR, Hunter MD, Watt AD (2008) The Ecology of Insects: Concepts and Applications, 2nd edn. Blackwell Scientific, Oxford, UK

Stokes CJ, Archer SR (2010) Niche differentiation and neutral theory: an integrated perspective on shrub assemblages in a parkland savanna. Ecology 91: 1152-1162

Štursová M, Šnajdr J, Cajthaml T, Bárta J, Šantrůčková H, Baldrian P (2014) When the forest dies: the response of forest soil fungi to a bark beetle-induced tree dieback. ISME J. 8: 1920-1931

Thompson R, Townsend C (2006) A truce with neutral theory: local deterministic factors, species traits and dispersal limitation together determine patterns of diversity in stream invertebrates. J. Anim. Ecol. 75: 476-484

Tilman D (1982) Resource Competition and Community Structure. (Mpb-17). Princeton University Press

Treu R, Karst J, Randall M, Pec GJ, Cigan PW, Simard SW, Cooke JEK, Erbilgin N, Cahill Jr JF (2014)

Decline of ectomycorrhizal fungi following a mountain pine beetle epidemic. Ecology 95: 1096-1103

Tucker CM, Shoemaker LG, Davies KF, Nemergut DR, Melbourne BA (2015) Differentiating between niche and neutral assembly in metacommunities using null models of $\beta$ - diversity. Oikos.

Tuomisto H, Ruokolainen K, Yli-Halla M (2003) Dispersal, environment, and floristic variation of western Amazonian forests. Science 299: 241-244

Vanschoenwinkel B, De Vries C, Seaman M, Brendonck L (2007) The role of metacommunity processes in shaping invertebrate rock pool communities along a dispersal gradient. Oikos 116: 1255-1266

Vasconcelos HL, Laurance WF (2005) Influence of habitat, litter type, and soil invertebrates on leaf-litter decomposition in a fragmented Amazonian landscape. Oecologia 144: 456-462

Vergnon R, Dulvy NK, Freckleton RP (2009) Niches versus neutrality: uncovering the drivers of diversity in a species-rich community. Ecol. Lett. 12: 1079-1090

Ward DF, New TR, Yen AL (2001) Effects of pitfall trap spacing on the abundance, richness and composition of invertebrate catches. J. Insect Cons. 5: 47-53

Wiedinmyer C, Barlage M, Tewari M, Chen F (2012) Meteorological impacts of forest mortality due to insect infestation in Colorado. Earth Interact. 16: 1-11

Williams RS, Marbert BS, Fisk MC, Hanson PJ (2014) Ground-Dwelling Beetle Responses to Long-

Peer] reviewing PDF | (2016:02:9286:2:1:NEW 26 Aug 2016) 
734 Term Precipitation Alterations in a Hardwood Forest. Southeast. Nat. 13: 138-155

735

736 Xiong Y, D’Atri JJ, Fu S, Xia H, Seastedt T (2011) Rapid soil organic matter loss from forest dieback in 737 a subalpine coniferous ecosystem. Soil Biol. Biochem. 43: 2450-245

738

739 Yu CH (2003) Resampling methods: concepts, applications, and justification. Pract. Assess. Res. Eval. 8: $740 \quad 1-23$. 
Table 1 Results of one-way PERMANOVA tests of grounddwelling arthropod community structure among years of a 5-year chronosequence of insect-induced tree mortality

\begin{tabular}{llrrrrc}
\hline Community & Source & $d f$ & SS & MSE & $F$ & $P$ \\
\hline \multirow{2}{*}{ Aboveground } & Year & 4 & 1.54 & 0.385 & 2.14 & 0.0002 \\
& Residual & 35 & 6.29 & 0.180 & & \\
& Total & 39 & 7.84 & & & \\
\hline \multirow{2}{*}{ Belowground } & Year & 4 & 1.68 & 0.420 & 1.51 & 0.0200 \\
& Residual & 25 & 6.94 & 0.277 & & \\
& Total & 29 & 8.62 & & & \\
\hline
\end{tabular}

761

762

763

764

765

766

767

768

769

770

771

772

773

774 
Table 2 Percent cover of vegetation types across a five-year chronosequence of insect-induced tree mortality

\begin{tabular}{|c|c|c|c|c|c|c|c|c|}
\hline Year & & Forb & $\mathrm{Gr}$ & mminoid & & Shrub & Tree & \\
\hline 0 & 1.5 & $( \pm 0.7)^{\mathrm{b}}$ & 0.9 & $( \pm 0.4)^{\mathrm{c}}$ & 3.4 & $( \pm 3.0)^{b}$ & 1.9 & $( \pm 1.0)$ \\
\hline 1 & 3.0 & $( \pm 0.6)^{\mathrm{ab}}$ & 1.5 & $( \pm 0.3)^{\mathrm{b}}$ & 3.6 & $( \pm 1.3)^{\mathrm{ab}}$ & 4.2 & $( \pm 2.9)$ \\
\hline 2 & 7.2 & $( \pm 2.2)^{\mathrm{a}}$ & 14.9 & $( \pm 9.5)^{\mathrm{a}}$ & 33.9 & $( \pm 12.2)^{\mathrm{a}}$ & 3.2 & $( \pm 1.7)$ \\
\hline 3 & 10.5 & $( \pm 3.6)^{\mathrm{a}}$ & 5.2 & $( \pm 1.3)^{\mathrm{a}}$ & 4.7 & $( \pm 3.5)^{b}$ & 0.7 & $( \pm 0.5)$ \\
\hline 4 & 7.9 & $( \pm 4.3)^{\mathrm{ab}}$ & 1.8 & $( \pm 0.5)^{\mathrm{bc}}$ & 11.3 & $( \pm 9.9)^{\mathrm{ab}}$ & 1.5 & $( \pm 0.7)$ \\
\hline $\begin{array}{l}P \text { - } \\
\text { value }\end{array}$ & & $<0.05$ & & 0.001 & & $<0.05$ & & $>0.05$ \\
\hline
\end{tabular}

791

792

793

794

795

796

797

798

799

800

801

802

803

804

805 
Table 3 Best fit models relating vegetation cover and soil factors to total abundance and Shannon diversity $\left(\mathrm{H}^{\prime}, \alpha\right.$-diversity) of the aboveground arthropod community

\begin{tabular}{llrccc}
\hline $\begin{array}{l}\text { Response } \\
\text { variable }\end{array}$ & Predictor variablet & $F$ & $P$ & adj. $R^{2}$ & BIC * \\
\hline \multirow{2}{*}{$\begin{array}{l}\text { Arthropod } \\
\text { abundance }\end{array}$} & Veg. cover & 16.33 & 0.0003 & & 80.1 \\
& Veg. species richness & 8.59 & 0.0058 & 0.40 & 76.8 \\
& Soil carbon (\%) & 4.46 & 0.0416 & & 75.8 \\
\hline Arthropod & Shrub cover & 6.54 & 0.0149 & & 35.2 \\
diversity & Soil carbon (\%) & 6.48 & 0.0153 & 0.26 & 33.9 \\
$\left(\right.$ Shannon $\left.\mathrm{H}^{\prime}\right)$ & Rock cover & 3.78 & 0.0598 & & 33.7 \\
\hline
\end{tabular}

*Bayesian information criterion (BIC) cumulative values with the addition of the given line's predictor; in both cases, all three listed predictors were retained in the best fit model--i.e., the lowest BIC score of all models. $†$ Possible predictor variables included total vegetation cover, vegetation species richness, forb cover, graminoid cover, tree cover, shrub cover, and rock cover; along with soil moisture, $\mathrm{C}, \mathrm{N}, \mathrm{C}: \mathrm{N}$, DOC, $\mathrm{NH}_{4}{ }^{+}$, and $\mathrm{pH}$. Variables retained in best fit models were screened for collinearity to avoid over-fitting models. Belowground arthropod measures were not significantly influenced by vegetation or soil properties. 


\section{Figure Legends}

810

811 Figure 1: Abundance and Shannon diversity $\left(\mathrm{H}^{\prime}\right)$ of aboveground and belowground arthropod

812 communities sampled along a five-year chronosequence of insect-induced tree mortality. Box

813 and whisker plots show the median (center line), the $1^{\text {st }}$ and $3^{\text {rd }}$ quartiles (shaded boxes), and the

8141.5 inter-quartile range or $\sim 97 \%$ of variation in the untransformed data (whisker bars). Boxes

815 with different letters are significantly different $(P<0.05)$ via LSD means comparisons following

816 one-way ANOVA.

817

818 Figure 2: Non-metric multi-dimensional scaling (NMDS) ordination based on Bray-Curtis

819 distances comparing the structure of aboveground (a) and belowground (b) arthropod

820 communities from samples collected along a five-year chronosequence of insect-induced tree

821 mortality. Chronosequence years with different letters in the legend indicate communities that

822 are significantly different (PERMANOVA $P<0.05)$.

823

824 Figure 3: Null deviation values from aboveground and belowground arthropod communities

825 sampled along a five-year chronosequence of insect-induced tree mortality. Null deviation values

826 close to zero indicate species compositions that deviate less from random suggesting a greater

827 relative influence of stochastic processes on community assembly, larger values (negative or

828 positive) indicate increasing deviation from random and suggest greater relative influence of

829 deterministic processes. Null deviation values of above- and belowground communities

830 significantly differ within chronosequence years 2 and 3 as indicated by an asterisk (*) above the

831 higher symbol.

832

833 Figure 4: Vegetation species richness (a) and aerial cover (b) along a five-year chronosequence

834 of insect-induced tree mortality. Box and whisker plots show the median (center line), the $1^{\text {st }}$ and

$8353^{\text {rd }}$ quartiles (shaded boxes), and the 1.5 inter-quartile range or $\sim 97 \%$ of variation in the

836 untransformed data (whisker bars). Boxes with different letters are significantly different $(P<$

837 0.05) via LSD means comparisons following one-way ANOVA. 

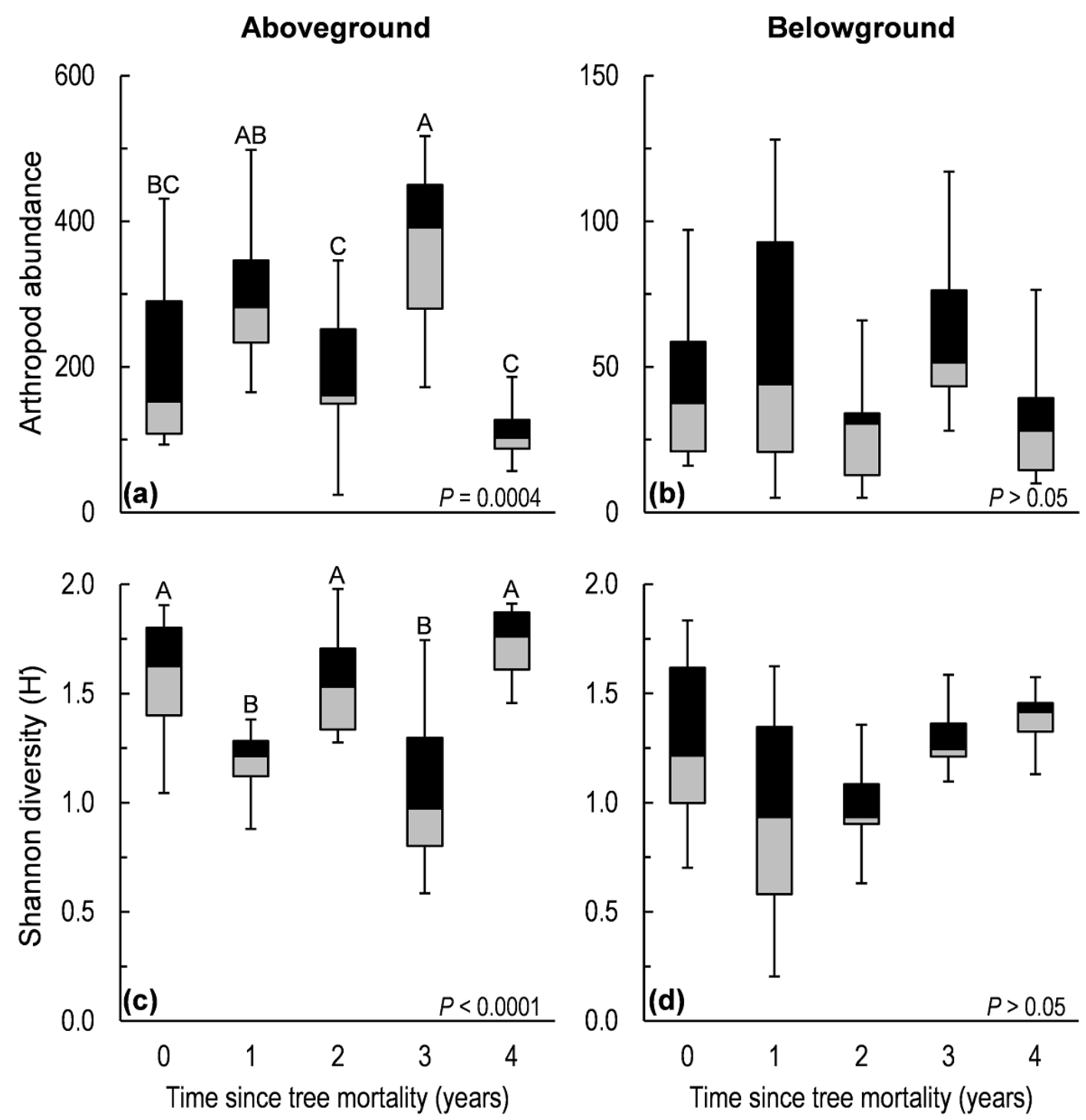


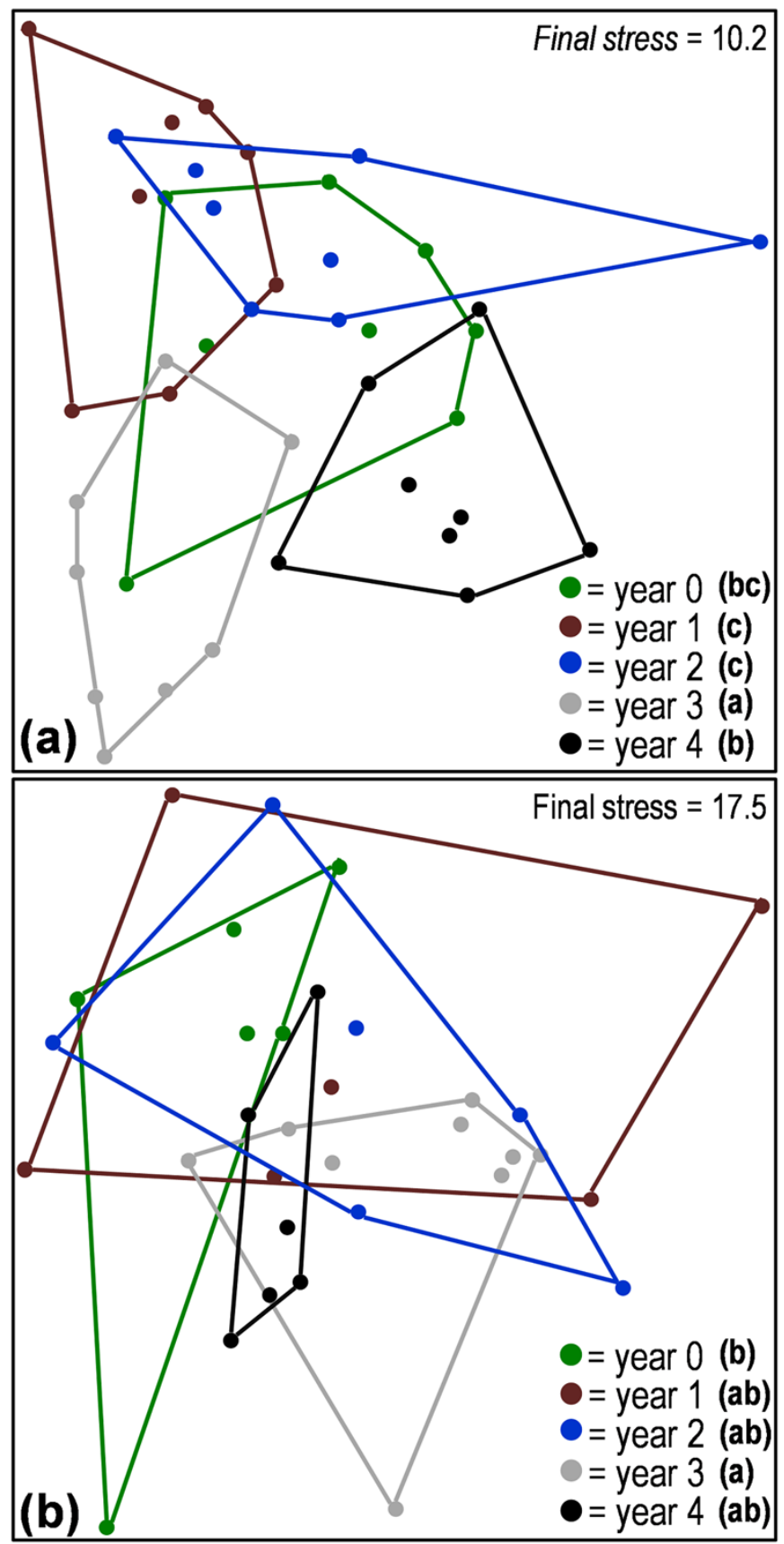




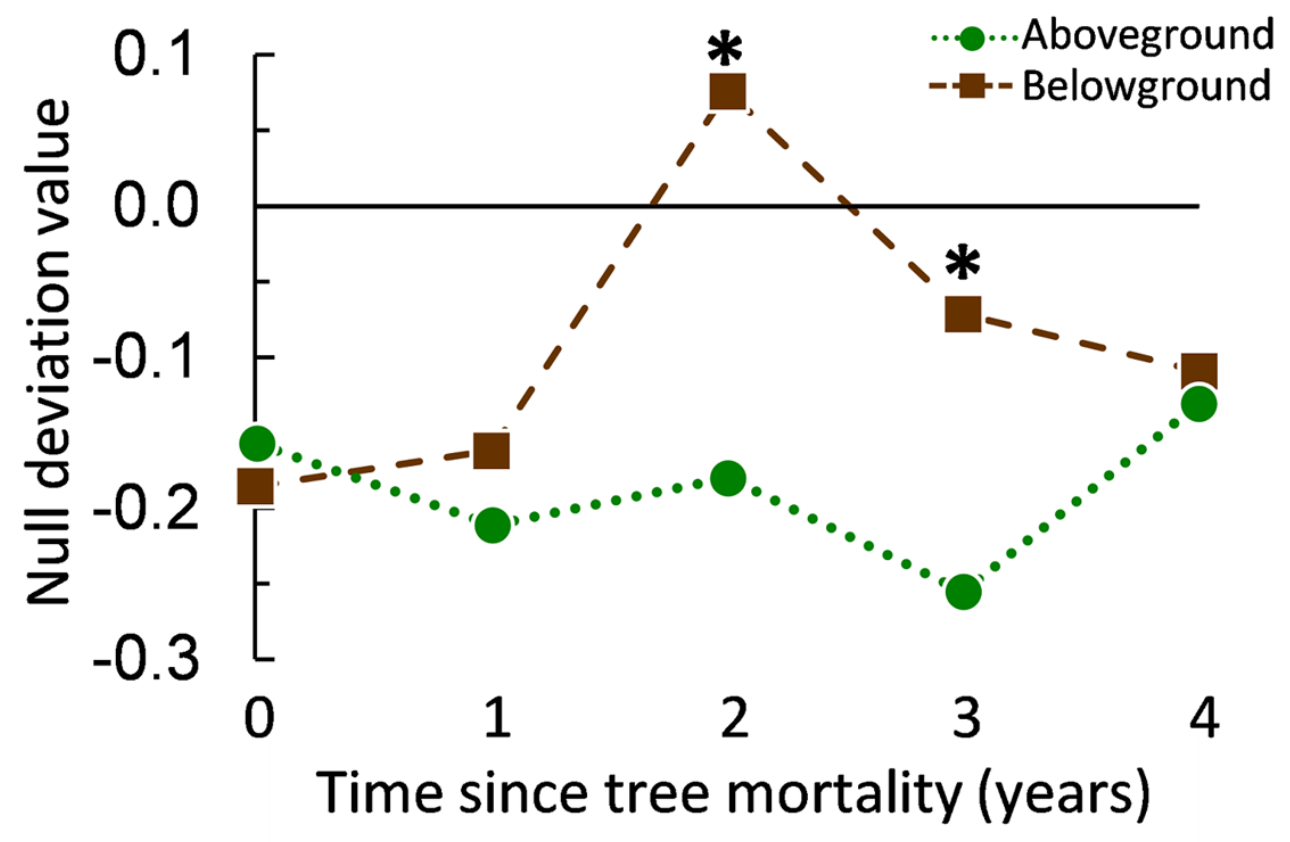

841

842 

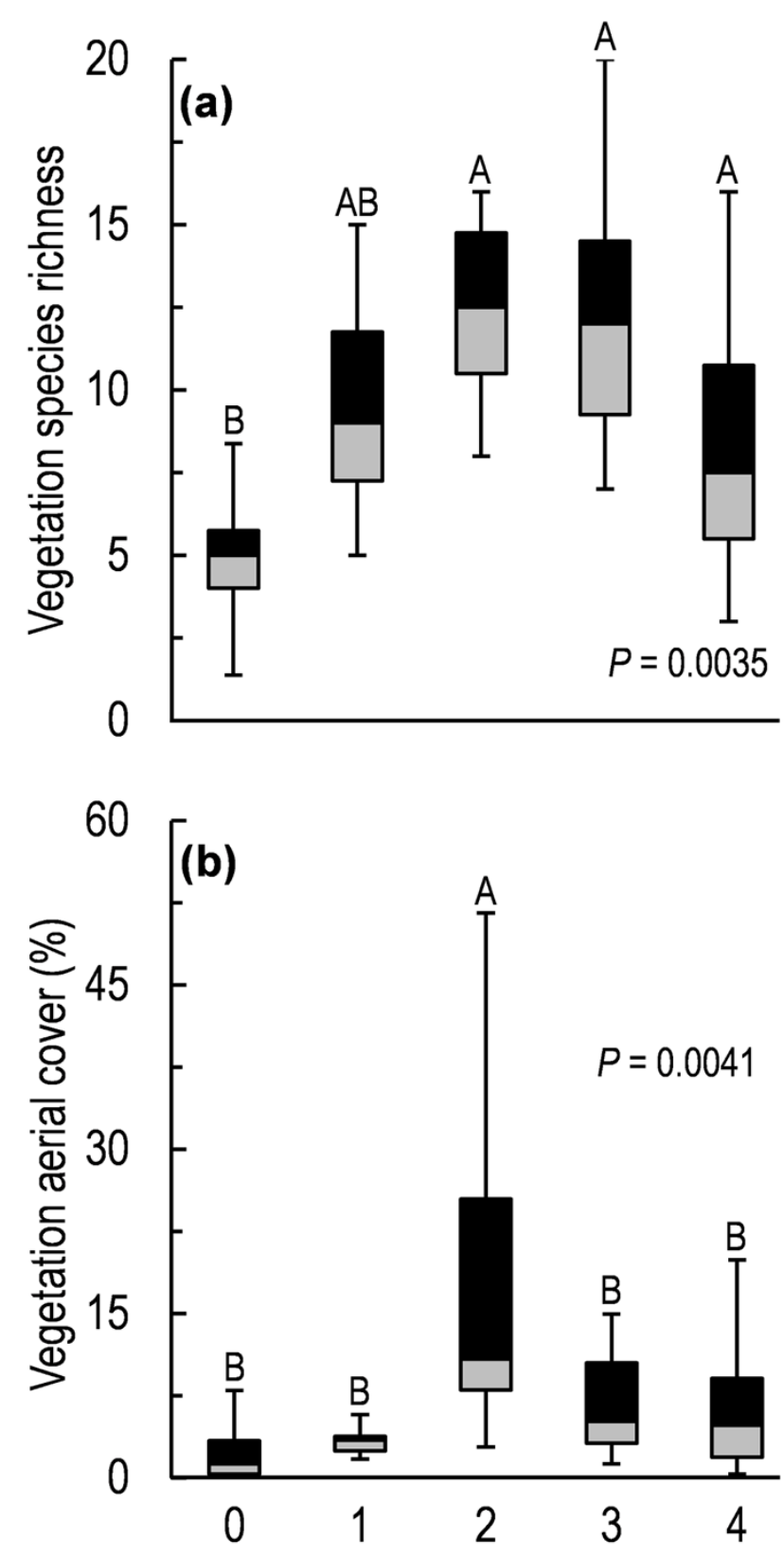

Time since tree mortality (years) 